Mirjana Šnjarić: Leksičke nepodudarnosti kolokacijskih obrazaca u njemačkome, engleskome i hrvatskome općeznanstvenom jeziku te njihov prikaz u e-rječnicima općeznanstvenoga nazivlja

\title{
Leksičke nepodudarnosti kolokacijskih obrazaca u njemačkome, engleskome i hrvatskome općeznanstvenom jeziku te njihov prikaz u e-rječnicima općeznanstvenoga nazivlja
}

\author{
Mirjana Šnjarić \\ Filozofski fakultet Sveučilišta u Zagrebu \\ mirjana.snjaric1@gmail.com
}

SAŽETAK: Rad se bavi transdisciplinarnim općeznanstvenim glagolsko-imeničkim kolokacijama i njihovim leksičkim nepodudarnostima u njemačkome, engleskome i hrvatskome općeznanstvenom jeziku - npr. Aspekt(e)/Problem(e) herausstellen; (to) highlight/emphasize point out aspects; istaknuti/ /naglasiti aspekt(e)/problem(e). Kontrastivna i prijevodna analiza ograničena je na odabrane primjere kolokacija u njemačkome i engleskome općeznanstvenom jeziku te na usporedbu s njihovim kontrastivnim korespondentima u hrvatskom jeziku i uspostavu prijevodnih ekvivalenata u trima jezicima.

Jedan od ciljeva rada jest uputiti na potrebu izrade novih vrsta višejezičnih i višenamjenskih elektroničkih rječnika s poboljšanom obradbom općeznanstvenih glagolsko-imeničkih kolokacija. Drugi cilj jest rasvijetliti kolokocijsku problematiku u tom području jezika i ponuditi prijedlog da se nepodudarni kolokacijski obrasci iscrpnije prikažu u novom trojezičnom e-rječniku općeznanstvenoga jezika na temelju potvrda stvarne primjene u širem sintagmatskom okruženju u suvremenom znanstvenom korpusu. Takvo sintagmatsko okruženje prikazivalo bi i opisivalo tip znanstvene djelatnosti koja se ostvaruje u suodnosu glagola i imenice ispod razine izolirane pojedinačne prijevodne istovrijednice i zauzima odgovarajuće mjesto u strukturi znanstvenoga teksta u trima jezicima. Krajnji cilj prvoga šireg istraživanja glagolsko-imeničkih kolokacija triju jezika jest predstaviti i prikazati popis tipičnih i karakterističnih općeznanstvenih kolokacija s prijevodnim istovrijednicama ili mogućim prijevodnim rješenjima koja bi na kraju trebala biti opisana i prikazana u novom trojezičnom elektroničkom rječniku transdisciplinarnoga općeznanstvenog nazivlja triju jezika.

Kao izvor hrvatskih glagolsko-imeničkih kolokacija korišten je suvremeni korpus hrvatskoga znanstvenoga jezika. Njemački mrežni rječnik Digitales Wörterbuch der deutschen Sprache (DWDS) poslužio je kao izvor kolokacijskih obavijesti za njemački jezik, dok je mrežni rječnik Glosbe korišten kao izvor za engleske kolokacije.

Ključne riječi: općeznanstveni jezik; transdisciplinarne glagolsko-imeničke kolokacije; hrvatski jezik; njemački jezik; engleski jezik; trojezični e-rječnik 


\section{Uvod}

Polazište ovoga istraživanja jezična su sredstva za oblikovanje općeznanstvene djelatnosti koja se nalaze na razini višoj od pojedinačne riječi i njihov prikaz u strukturi rječničkoga članka u dvojezičnim i budućem višejezičnom elektroničkom rječniku. Predstavlja se početni plan izrade projekta usmjerenoga prema stvaranju višejezičnoga internetskoga kolokacijskog rječnika hrvatskog u kombinaciji s njemačkim i engleskim općeznanstvenim jezikom. Raspravljajući o pitanjima vezanim uz primjenu mrežno dostupnih leksikografskih izvora njemačkoga i engleskoga jezika primjenjivih u procesu uspostave semantičke ekvivalentnosti između glagolsko-imeničkih kolokacija hrvatskoga, njemačkoga i engleskoga jezika, razmatra se mogućnost poboljšanja pokrivenosti ovoga područja leksika i leksičkih kombinacija te pružanja kvalitativno vidljivije i dostupnije korisničke usluge. Među složenim leksičkim strukturama i izrazima te ustaljenim jezičnim sredstvima za oblikovanje znanstvenoga teksta nalaze se brojne tipične i karakteristične općeznanstvene glagolsko-imeničke kolokacije, uobičajene u znanstvenom pisanju u određenoj jezičnoj i znanstvenoj zajednici. Zbog prividne sličnosti i povezanosti pojedinih kolokacijskih sastavnica (osnova + kolokator) s općim jezikom gotovo su neupadljive te ostaju skrivene $u$ strukturi znanstvenoga teksta između termina $u$ užem smislu. Također su zbog nedostatne leksikografske pokrivenosti ${ }^{1}$ i tipografske neoznačenosti u općim dvojezičnim rječnicima često nedostupne za korisnika rječnika s hrvatskim kao materinskim jezikom koji piše na njemačkom ili engleskom kao ciljnom znanstvenom jeziku.

O složenosti pojave glagolsko-imeničkih kolokacija u općeznanstvenom njemačkom jeziku pisali su Wallner (2014) te Meißner i Wallner (2016), no o kontrastivnoj usporedbi s kolokacijama u nekoj ciljnoj jezičnoj i znanstvenoj zajednici do sada ne postoji velik broj jezikoslovnih rasprava. Postoje radovi koji se odnose na analizu glagola kojima se opisuju komunikacijski činovi u općeznanstvenome jeziku, poglavito njemačkom u kontrastu s engleskim jezikom (usp. Fandrych 2002. ${ }^{2}$ i Siepmann 2019) kao prevladavajućim jezikom znanstvene komunikacije. Pritom se zanemaruje kontrastiranje s ostalim znanstvenim jezicima (koji nisu engleski), poput empirijskoga istraživanja o obilježjima tekstova i konvencijama pisanja u paralelnom korpusu sastavljenom od tekstova socioloških časopisa objavljivanih na njemačkom i talijanskom jeziku (usp. Heller 2012). Može se ustvrditi da međujezična usporedba općeznanstvenoga jezikoslovlja, odnosno pojedinih leksičkih sastavnica općeznanstvenoga jezika nije dovoljno obuhvaćena u istraživanjima, a posebice kad se radi o

1 Što su pokazali rezultati istraživanja o pokrivenosti glagolsko-imeničkih kolokacija u općim dvojezičnim rječnicima provedeni u okviru doktorske disertacije Šnjarić (2018).

2 Fandrych (2002) je u korpusu utvrdio različit brojčani odnos glagola s odgovarajućom funkcijom u njemačkome i engleskome znanstvenom diskursu, a neproporcionalnost pripisuje različitoj konceptualizaciji znanstvene djelatnosti i procesa spoznaje u pojedinim jezičnim i znanstvenim zajednicama. 
istraživačkim radovima s leksikografskim težištem u usporedbi s jezicima koji se smatraju perifernim jezicima znanstvene komunikacije. Stoga se ovaj rad može smatrati doprinosom međujezičnoj usporedbi hrvatskog s njemačkim i engleskim kao ciljnim znanstvenim jezicima i doprinosom korpusno utemeljenim istraživanjima obilježja općeznanstvenih leksičkih sredstava hrvatskoga jezika čiji popis i opis jesu preduvjeti bolje leksikografske pokrivenosti.

\section{Metodologija i ciljevi}

U radu se istražuju i uspoređuju glagolsko-imeničke kolokacije sljedećih strukturnih tipova:

Glagol + imenica (objekt dativ ili akuzativ)

Glagol + imenica (subjekt ${ }_{\text {nominativ }}$ )

Glagol + imenica (prijedložni objekt)

Istraživanje se provodi korpusnim pristupom i prijevodnom analizom. Navode se početne faze rada na razvoju novoga leksičkog izvora hrvatskoga akademskog jezika, čiji prvi i osnovni cilj jest izrada korpusa i empirijska analiza općega leksika hrvatskoga akademskoga jezika. Slijedi popis hrvatskih općeznanstvenih glagola utvrđenih u korpusu te tablični prikaz i odabir nekoliko najčestotnijih, na temelju kojih će se u korpusu utvrditi relevantno sintagmatsko okruženje, odnosno karakteristične i tipične glagolsko-imeničke kolokacije uobičajene u pisanom hrvatskom znanstvenom diskursu.

Korpus koji je izrađen s ciljem dobivanja novih leksičkih obavijesti o suvremenom hrvatskom općeznanstvenom jeziku korišten kao izvor za opis i popis kolokacija, dostupan je na platformi SketchEngine. Sastoji se od doktorskih disertacija objavljivanih u razdoblju od 2010. do 2020. godine i članaka znanstvenih časopisa Republike Hrvatske iz područja humanističkih znanosti dostupnih u elektroničkom obliku putem portala Hrčak. Korpus broji ukupno 601,010 pojavnica i predstavlja suvremenu zbirku tekstova hrvatskoga znanstvenog jezika. Na temelju suvremenoga korpusa izrađuje se egzemplarni popis glagolsko-imeničkih kolokacija za usporedbu s njemačkim i engleskim općeznanstvenim kolokacijama i ugradnju u budući višejezični digitalni kolokacijski rječnik.

Drugi cilj koji je zadan u istraživanju jest na odabranim primjerima kolokacija triju (3) jezika - njemačkoga, hrvatskoga i engleskoga prikazati općeznanstvene glagolsko imeničke kolokacije, međujezične sličnosti i razlike te obrazložiti relevantnost kontrastiranja glagolsko imeničkih kolokacija s ostalim jezicima. Zatim povezati kolokacijske obavijesti dobivene iz postojećih njemačkih i engleskih jednojezičnih rječnika digitales Wörterbuch der deutschen Sprache(DWDS) koji sadržava podkorpus znanstvenih tekstova (usp. sliku 2) i ColloCaid koji služi kao pomoćno sredstvo za 
pronalaženje i utvrđivanje pravilnoga kolokatora te kao korisnička podrška u znanstvenom pisanju (usp. sliku 1), ali i njemačko-engleskoga digitalnog dvojezičnog rječnika Glosbe s kolokacijama utvrđenim u hrvatskom korpusu. Na taj način provjerit će se primjenjivost metode izvlačenja kolokacija relevantnih za ugradnju u višejezični kolokacijski rječnik. Krajnji cilj jest predstaviti preliminarne rezultate kontrastivne kolokacijske studije u trima (3) općeznanstvenim jezicima hrvatskome, njemačkome i engleskome jeziku.

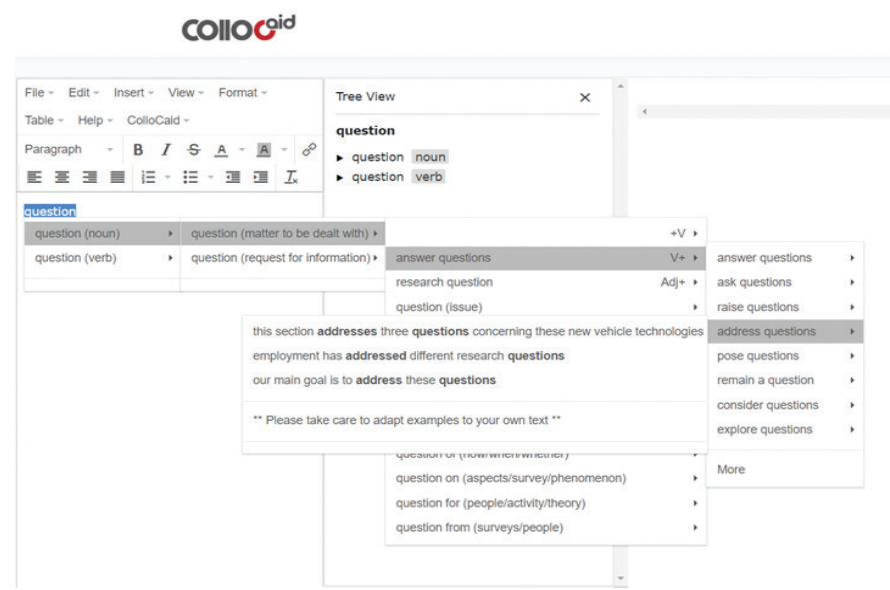

Slika 1. ColloCaid, engleski jednojezični kolokacijski rječnik

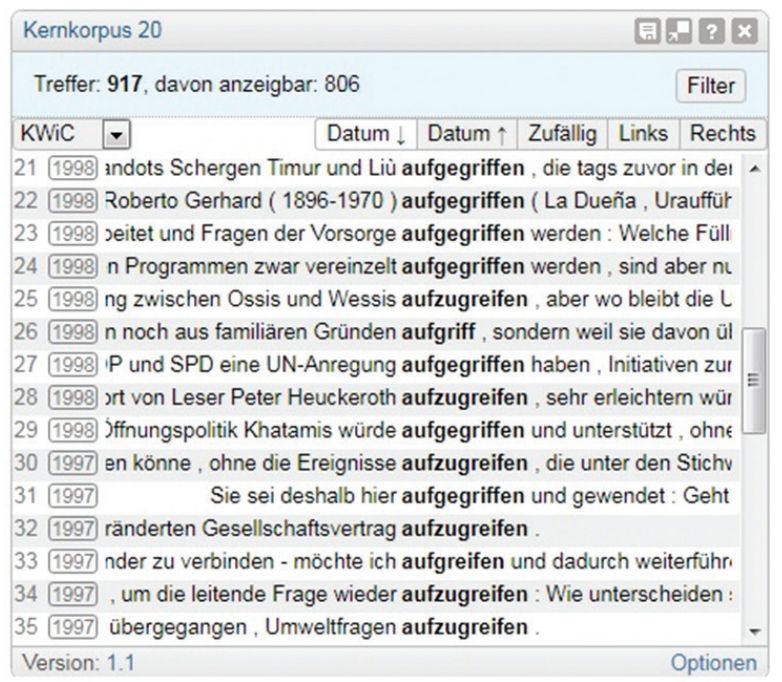

Slika 2. Analiza supojavničkog profila glagola »aufgreifen«s pomoću njemačkoga jednojezičnog digitalnog rječnika Digitales Wörterbuch der deutschen Sprache (DWDS). 


\section{Rezultati i rasprava}

Istraživanje se provodi polazno od odabranih primjera glagola hrvatskog općeznanstvenoga jezika. U ad hoc korpusu hrvatskoga znanstvenoga jezika izrađenom za potrebe ovoga istraživanja, s pomoću opcije Wordlist-frequency utvrđeni su najčestotniji hrvatski glagoli.

Tablica 1. Rezultati korpusne analize s popisom dvadeset (20) izdvojenih najčestotnijih glagola Verb (2,049 items $\mid 17,326$ total frequency)

Lema Apslolutna frekvencija

\begin{tabular}{|l|l|}
\hline 1 koristiti & 192 \\
\hline 2 dati & 186 \\
\hline 3 objavljivati & 169 \\
\hline 4 navoditi / navesti & 192 \\
\hline 5 citirati & 120 \\
\hline 6 pisati & 109 \\
\hline 7 dodijeliti & 62 \\
\hline 8 spremiti & 62 \\
\hline 9 prijaviti & 62 \\
\hline 10 predstavljati & 59 \\
\hline
\end{tabular}

\begin{tabular}{|l|l|}
\hline 11 sadržavati & 124 \\
\hline 12 pokazati & 111 \\
\hline 13 postojati & 53 \\
\hline 14 donositi & 50 \\
\hline 15 raditi & 47 \\
\hline 16 slijediti & 47 \\
\hline 17 nalaziti & 45 \\
\hline 18 utjecati & 41 \\
\hline 19 smatrati & 39 \\
\hline 20 prikazivati & 38 \\
\hline
\end{tabular}

Među najčestotnijim glagolima prikazanim u tablici 1 odabrano je nekoliko primjera za analizu. Na temelju glagola dobiven je preliminarni popis hrvatskih općeznanstvenih glagolsko-imeničkih kolokacija prikazan u tablici 2 za usporedbu s kolokacijama u dvama (2) ciljnim znanstvenim jezicima, njemačkom i engleskom.

U znanstvenom pisanju autor komunicira s potencijalnom čitateljskom publikom što se ostvaruje gramatičkim i leksičkim sredstvima preuzetim iz općega u znanstveni jezik. O općem kategorijalnom nazivlju i općem leksičkom fondu u području hrvatskoga znanstvenoga jezika usp. Silić (2006).

To područje znanstvenoga jezika Ehlich (1993) naziva »opći ili svakodnevni znanstveni jezik« njem. »allgemeine oder alltägliche Wissenschaftssprache«, dok se $\mathrm{u}$ engleskoj jezikoslovnoj literaturi nalazi naziv »common language of academia« (usp. Rheindorf i Huemer 2015), odnosno »general academic language« (Siepmann (2020).

Tako se primjerice u procesu pisanja u metakomentarima vlastitoga teksta postavljaju, odnosno oblikuju istraživačko pitanje i predmet proučavanja što autor jezično ostvaruje brojnim glagolsko-imeničkim kolokacijama općeznanstvenoga jezika s pojedinim leksičkim sastavnicama preuzetim iz općega u znanstveni jezik i prilagođenim potrebama znanosti. Za njih se u ciljnim znanstvenim jezicima zbog pre- 
feriranosti odabira kolokatora, odnosno »upadljivosti« kombiniranja leksičkih jedinica u pojedinim nacionalnim znanstvenim jezicima često ne pronalaze odgovarajuće prijevodne istovrijednice, već postoje kolokacijske praznine ili se može govoriti o stupnjevima kolokacijskih prijevodnih istovrijednica u hrvatskom, njemačkom i engleskom jeziku (usp. Šnjarić i Borucinsky 2020). Tako se u njemačkom općeznanstvenom jeziku pitanja postavljaju s tri (3) moguća kolokatora. Primjerice s glagolom stellen s refleksivnom zamjenicom: eine Frage stellt sich (primjer pod rednim brojem 1), ali i eine Frage stellen (2), kao i eine Frage aufwerfen (3) (»nabaciti pitanje«), što nije kolokator uobičajen u hrvatskom općeznanstvenom jeziku. No korpusna analiza pruža uvid u moguće glagolsko-imeničke obrasce kao što je u ovom slučaju iznijeti pitanje kao istovrijednicu njemačke kolokacije eine Frage aufwerfen.

Tablica 2. Glagoli (kolokatori) osnove »pitanje« potvrđeni u korpusu hrvatskog znanstvenoga jezika

\section{KORPUS HRVATSKOGA OZJ}

Hrvatski glagoli (kolokatori) u tematskom polju postavljanja / oblikovanja istraživačkoga pitanja

Morfosintaktički obrazac:

Glagol + Imenica (objekt)

Postavljati pitanje

Obrađivati pitanja

Potencirati pitanje

Istražiti (specifična) pitanja

Razmatrati (temeljna) pitanja

Iznositi (osnovna) pitanja

Riješiti pitanje
Morfosintaktički obrazac:

Glagol + Imenica (subjekt)

Otvoriti (otvorila su se pitanja)

Inhibirati (pitanje inhibira)

Normirati (pitanje normira)

Susretati (susreće se pitanje)

Rezultirati (pitanje rezultira)

Sadržavati (pitanje sadrži)

Problematizirati pitanja

Postoje brojne kolokacije u tematskom polju postavljanja pitanja u znanstvenom jeziku (1-16): sich einer Frage zuwenden, eine Frage aufgreifen, einer Frage nachgehen, eine Frage verfolgen, eine Frage drängt sich auf, eine Frage eingehen i dr., što je prikazano u tablici 2. polazno od njemačkoga prema engleskome i hrvatskome jeziku. Međutim u digitalnom hrvatsko-engleskom rječniku Glosbe često nisu razvidne prijevodne istovrijednice karakteristične i tipične za općeznanstveni jezik jer se mi- 
Mirjana Šnjarić: Leksičke nepodudarnosti kolokacijskih obrazaca u njemačkome, engleskome i hrvatskome općeznanstvenom jeziku te njihov prikaz u e-rječnicima općeznanstvenoga nazivlja

ješaju s kolokacijama uobičajenim u razgovornim stilu, kao što pokazuju primjeri u tablici 3. (kolokatori pod rednim brojem 7 označeni oznakom asterisk*).

Tablica 3. Međujezična usporedba kolokacijskih obrazaca s imenicom »pitanje« u trima općeznanstvenim jezicima

\section{TIPIČNE I KARAKTERISTIČNE OPĆEZNANSTVENE KOLOKACIJE}

Glagolsko-imeničke kolokacije
postavljanja pitanja / propitivanja
predmeta znanstvenoga
promatranja u njemačkome opće-
znanstvenom jeziku

eine Frage stellt sich (Nom.)

eine Frage stellen (Akk.)

eine Frage aufwerfen (Akk.)

sich einer Frage zuwenden (Dat.)

einer Frage nachgehen (Dat.)

eine Frage verfolgen (Dat.)

eine Frage (wieder) aufgreifen

(Akk.)

eine Frage drängt sich auf (Nom.)

auf eine Frage eingehen (Akk.)

eine Frage betrachten (Akk.)

sich einer Frage widmen (Dat.)

sich mit einer Frage beschäftigen

(Dat.)

sich mit einer Frage befassen (Dat.)

eine Frage behandeln (Akk.)

eine Frage erörtern (Akk.)

eine Frage beleuchten / ausleuchten (Akk.)
Glagolsko-imeničke kolokacije postavljanja pitanja / propitivanja predmeta znanstvenoga promatranja u engleskome općeznanstvenom jeziku

to ask / to raise / to pose a question

to ask / to raise a question

to ask/to raise a question

to adress an issue /question / to focus on

to pursue a question

to explore / to adress a topic

to adress / to raise / (*pick up)

/ (*take up) a question

it leads to the question / the obvious question is /

to adress an issue / to raise / to turn to an issue /

to consider a question

to address /discuss /focus on a question / to confront a question

to deal with a question

to deal with a question

to adress the question

to consider / to discuss an issue

to pursue a question
Glagolsko-imeničke kolokacije postavljanja pitanja / propitivanja predmeta znanstvenoga promatranja u hrvatskome općeznanstvenom jeziku

postavlja se pitanje

postaviti / postavljati pitanje iznijeti / iznositi / pokrenuti / pokretati / postavljati pitanje usredotočiti se na pitanje proučiti / proučavati pitanje istražiti / istraživati pitanje prihvatiti / preuzeti / primijeniti pitanje / baviti se / *pozabaviti se nameće se pitanje

baviti se pitanjem promatrati pitanje posvetiti se pitanju

baviti se baviti se obraditi / obrađivati pitanje razmatrati / razmotriti rasvijetliti / rasvjetljivati

Iz tablice 3. vidi se da također postoji i različit broj potencijalnih glagola $u$ funkciji kolokatora te kolokacijska neproporcionalnost i idiosinkratičnost odabira kolokatora u odnosu na engleski i hrvatski jezik. 
No u postojećim dvojezičnim općim rječnicima njemačko-hrvatskom i hrvatsko-njemačkom iz određenih natukničkih članaka najčešće ne proizlazi stupanj tipičnosti kolokatora ispod granice pojedinačne (izolirane) prijevodne istovrijednice i granice primjene glagolsko-imeničke kolokacije u znanstvenom kontekstu (usp. Šnjarić 2018). Tako da korisnik zbog nepokrivenosti ovoga područja često nema predodžbu o području primjene glagolsko-imeničkih kolokacija općeznanstvenoga jezika i njihovu mjestu u procesu pisanja ili prevođenja znanstvenoga teksta sa stranoga na materinski jezik (J2-J1), a još manje s materinskoga na strani znanstveni jezik (J1-J2), bilo na njemački, bilo na engleski.

U nastavku se ilustriraju metode odabira i utvrđivanja imeničkih kolokacija u korpusu hrvatskoga znanstvenoga jezika.

Rezultati dobiveni međujezičnom usporedbom triju jezika pokazuju da postoje znatne značenjske razlike koje proizlaze iz kolokacijskoga suodnosa glagola i imenice u trima opće znanstvenim jezicima. Tako da je često nemoguće uspostaviti leksičku ekvivalentnost u odnosu $1: 1$ već se može govoriti o kontinuumu kolokacijskih značenja od potpuno prozirnih (sich mit einer Frage beschäftigen / befassen) s dvama sinonimnim kolokatorima u njemačkome jeziku, hrv. »baviti se pitanjem《, engl. »to deal with a question « do poluprozirnih kolokacija (einer Frage nachgehen »proučiti / proučavati pitanje«). Glagol nachgehen $\mathrm{u}$ općem jeziku »pratiti«, »slijediti« u suodnosu s imenicom Frage »pitanje« u znanstvenom kontekstu dobiva dopunsko, specijalizirano značenje »proučavati / istražiti / istraživati pitanje«. Svaki od jezika rabi preferirane kolokatore (glagole) koji se ne preferiraju uvijek i u ciljnim znanstvenim jezicima.

Iz tablice 4. razvidno je da jezici ne nude isti broj G-I kolokacija za isto specifično tematsko polje. Tako se za hrvatsku G-I kolokaciju baviti se pitanjem pronalazi nekoliko kolokacija u njemačkom jeziku: eine Frage behandeln / sich mit einer Frage beschäftigen /sich mit einer Frage befassen / auf eine Frage eingehen i eine Frage (wieder) aufgreifen $\mathrm{s}$ različtom primjenom na različitim mjestima $\mathrm{u}$ znanstvenom tekstu. Tako s kolokacijom auf eine Frage eingehen autor najčešće najavljuje prijelaz s odlomka na odlomak, dok se kolokacija eine Frage (wieder) aufgreifen pojavljuje uvodno, primjerice $u$ opisu odabira pristupa znanstvenom istraživanju koji se primjenjuje $u$ radu. 
Tablica 4. Općeznanstvene glagolsko-imeničke kolokacije u hrvatskome, njemačkome i engleskome jeziku

\begin{tabular}{|c|c|c|c|}
\hline Glagoli & $\begin{array}{l}\text { Glagolsko imeničke } \\
\text { kolokacije u hrvatsko- } \\
\text { me jeziku }\end{array}$ & $\begin{array}{l}\text { Glagolsko imeničke } \\
\text { kolokacije u njemačkome } \\
\text { jeziku (DWDS) }\end{array}$ & $\begin{array}{l}\text { Glagolsko imeničke } \\
\text { kolokacije u englesko- } \\
\text { me jeziku }\end{array}$ \\
\hline baviti se $(18)^{3}$ & $\begin{array}{l}\text { pitanjem / problematikom } \\
\text { temom }\end{array}$ & $\begin{array}{l}\text { eine Frage / Problematik } \\
\text { aufgreifen / auf ein Thema } \\
\text { eingehen / sich mit e-er Frage } \\
\text { beschäftigen /s. befassen / ein } \\
\text { Thema bahandeln }\end{array}$ & $\begin{array}{l}\text { to adress / to raise a } \\
\text { question/an issue /to deal } \\
\text { with a question / to focus } \\
\text { on an issue }\end{array}$ \\
\hline davati dati (16) & $\begin{array}{l}\text { doprinos / primjer / } \\
\text { pregled / teorijske } \\
\text { postavke }\end{array}$ & $\begin{array}{l}\text { einen Beitrag leisten / ein } \\
\text { Beispiel geben / } \\
\text { einen Überblick geben / } \\
\text { theoretische Grundlagen } \\
\text { geben }\end{array}$ & $\begin{array}{l}\text { to contribute to / to set an } \\
\text { example /to give an } \\
\text { overwiew / to provide } \\
\text { theoretical foundations }\end{array}$ \\
\hline $\begin{array}{l}\text { istraživati / } \\
\text { istražiti (106) }\end{array}$ & teorije / strukturu & $\begin{array}{l}\text { eine Theorie /Struktur } \\
\text { untersuchen }\end{array}$ & $\begin{array}{l}\text { to explore a theory /to } \\
\text { analyze the structure }\end{array}$ \\
\hline $\begin{array}{l}\text { razraditi / } \\
\text { razradivati } \\
(106)\end{array}$ & hipotezu / teoriju & $\begin{array}{l}\text { eine Theorie herausarbeiten / } \\
\text { eine Hypothese entwickeln }\end{array}$ & $\begin{array}{l}\text { to elaborate a theory / to } \\
\text { develop a hypothesis }\end{array}$ \\
\hline $\begin{array}{l}\text { isticati / } \\
\text { istaknuti (106) }\end{array}$ & sličnosti / razlike & $\begin{array}{l}\text { herausstellen / herausheben / } \\
\text { hervorheben /betonen / } \\
\text { herausstreichen Ähnlichkei- } \\
\text { ten / Unterschiede }\end{array}$ & $\begin{array}{l}\text { to emphasize similarities / } \\
\text { differences }\end{array}$ \\
\hline $\begin{array}{l}\text { navesti / } \\
\text { navoditi (87) }\end{array}$ & primjer & $\begin{array}{l}\text { ein Beispiel herausgreifen / } \\
\text { aufgreifen / vorführen / } \\
\text { aufführen / anführen }\end{array}$ & $\begin{array}{l}\text { to demonstrate with an } \\
\text { example / to list examples } \\
\text { / to exemplify / to }\end{array}$ \\
\hline
\end{tabular}

No zbog velikoga broja kolokatora koji se nude u strukturi rječničkog članka u općim rječnicima često su nejasne granice primjenjivosti u znanstvenom kontekstu ispod pojedinačne prijevodne istovrijednice pa se govornik i prevoditelj susreću s poteškoćama pronalaženja najprikladnijega kolokatora za primjenu u znanstvenom tekstu.

Međujezične značenjske razlike koje proizlaze iz kolokacijskoga suodnosa glagola i imenice u znanstvenom jeziku kao i kolokacijske asimetrije koje dolaze do izražaja u kontrastu s ostalim jezicima i dokaz su da postoji potreba za novim korisničkim alatima koji bi bolje obuhvaćali i prikazivali G-I općeznanstvene kolokacije. Tako bi hrvatski autori u procesu pisanja znanstvenog teksta dobili lako dostupno sredstvo provjere i samoprovjere i to kroz usporedbu s kolokacijama u onom stranom znanstvenom jeziku kojim su najbolje ovladali i koji je ujedno i prevladavajući jezik znanstvenih publikacija, a to je engleski.

\footnotetext{
3 Čestotnost glagola potvrđena u korpusu.
} 
Novi e-rječnik bio bi dvosmjeran (J1-J2) i (J2-J1) te bi putem mrežne poveznice zainteresiranom korisniku s hrvatskim kao materinskim jezikom omogućavao brzu i jednostavnu provjeru pravilnosti kolokacija polazno od hrvatskoga prema njemačkom ili engleskom jeziku i polazno od njemačkoga prema hrvatskome ili prema engleskome općeznanstvenom jeziku.

Novo korisničko sredstvo s prikazom sintagmatskog okruženja koje je posebno uobičajeno, tj. tipično i primjereno znanstvenom kontekstu. Korisniku bi pružilo osjećaj sigurnosti da postupa na pravilan način ako upotrijebi takvu kolokaciju, a odbaci neku drugu potencijalno moguću, ali neuobičajenu i nekarakterističnu u uporabi u znanstvenom jeziku.

\section{Zaključak}

U ovom radu ilustrirane su metode pronalaženja, utvrđivanja te odabira glagolsko-imeničkih kolokacija u novom korpusu suvremenoga hrvatskog znanstvenoga jezika. Sastavljen je popis kolokacija relevantnih za unos u specijalizirani e-rječnik općeznanstvenih kolokacija triju jezika te su predstavljeni rezultati preliminarne kolokacijske studije u hrvatskome, njemačkome i engleskome jeziku. Analizirana je mogućnost povezivanja s kolokacijama njemačkoga i engleskoga jezika dostupnih putem digitalnih rječnika njemačkoga i engleskoga jezika. Jedan od ciljeva istraživanja bio je na odabranim primjerima uputiti na međujezične razlike u tvorbi kolokacijskih obrazaca u trima jezicima te ukazati na ulogu kolokacija kao važne sastavnice prikaza općeznanstvene djelatnosti u strukturi rječničkoga članka kako bi ih se učinilo kvalitativno vidljivijima i dostupnijima hrvatskim korisnicima. Krajni cilj jest stvoriti trojezični akademski kolokacijski e-rječnik koji povezuje leksikografski prikaz općeznanstvenih glagolsko-imeničkih kolokacija hrvatskoga jezika s kolokacijama njemačkoga i engleskoga općeznanstvenoga jezika. Jedan od aspekata budućega rječnika jest povezati glagolsko-imeničke kolokacije triju (3) jezika i prikazati ih kao leksičke cjeline i prijevodne jedinice s funkcijom u znanstvenom kontekstu. Inovativnost pristupa glagolsko-imeničkim kolokacijama sastoji se u činjenici da sada nije objavljen trojezični kolokacijski rječnik koji bi obuhvaćao samo općeznanstvene glagolsko-imeničke kolokacije. Rječnik je namijenjen govornicima hrvatskoga jezika i autorima koji pišu na njemačkom ili engleskom kao ciljnim znanstvenim jezicima, ali se može koristiti i obratno, polazno od njemačkoga ili engleskoga prema hrvatskome znanstvenom jeziku. Dakle ciljna skupina jesu poglavito hrvatski autori koji pišu na nekom stranom znanstvenom jeziku, ali bit će jednako koristan studentima, pre- 
voditeljima, tumačima i nastavnom osoblju u pripremama za nastavni rad sa studentima, kao i obratno: govornicima njemačkoga i engleskoga jezika koji uče hrvatski jezik i namjeravaju ovladati znanstvenim pisanjem na hrvatskom jeziku. Kolokacije navedene u rječniku pripadat će trima specifičnim sintaktičkim obrascima, »glagol + imenica kao subjekt«, »glagol + imenica kao izravni objekt«, »glagol + prijedložni objekt $\ll$.

\section{LITERATURA}

Ehlich, Konrad (1993). Deutsch als fremde Wissenschaftssprache, fahrbuch Deutsch als Fremdsprache $19,13-42$.

Fandrych, Christian (2002). Herausarbeiten vs. illustrate: Kontraste bei der Versprachlichung von Sprechhandlungen in der englischen und deutschen Wissenschaftssprache. Mehrsprachige Wissenschaft - europäische Perspektiven. Eine Konferenz zum Europäischen fahr der Sprachen 2001. Hrsg. Ehlich, Konrad. Institut für Deutsch als Fremdsprache/Transnationale Germanistik. München.

Heller, Dorothee (2012). Wissenschaftskommunikation im Vergleich: Fallstudien zum Sprachenpaar Deutsch-Italienisch. In: Ehlich, K. (hrsg.), Arbeiten zur Sprachanalyse 57. Frankfurt am Main. Peter Lang Verlag.

Meißner, Cordula, Wallner, Franziska (2016). Persuasives Handeln im wissenschaftlichen Diskurs und seine lexikographische Darstellung: das Beispiel der Kollokation Bild zeichnen, Acta Universitatis Wratislaviensis, No 3742, Studia Linguistica, Wroclaw.

Rheindorf, Markus, Huemer, Birgit (2015). Developing a German-English Dictionary of the Common Language of Academia, fournal of Academic Writing, 5/1.

Siepmann, Dirk (2019). General academic language in German-English translation: a nuanced view, Lebende Sprachen, 64(2), 230-268.

Siepmann, Dirk (2020). Wörterbuch der allgemeinen Wissenschaftssprache: Wörter, Wendungen und Mustertexte (Deutsch und Englisch). Deutscher Hochschulverband.

Silić, Josip (2006). Funkcionalni stilovi hrvatskoga jezika. Disput. Zagreb.

Šnjarić, Mirjana (2018). Glagolsko-imeničke kolokacije u općeznanstvenom hrvatskom i njemačkom jeziku. Doktorski rad. Filozofski fakultet. Zagreb.

Šnjarić, Mirjana, Borucinsky, Mirjana (2020). Glagolsko-imeničke kolokacije hrvatskoga, njemačkoga i engleskoga općeznanstvenog jezika u općoj dvojezičnoj e-leksikografiji. Rasprave: časopis Instituta za hrvatski jezik i jezikoslovlje. Vol. 46, No 2.

Wallner, Franziska (2014). Kollokationen in Wissenschaftsprachen: zur lernerlexikographischen Relevanz ihrer Gebrauchsspezifika. Tübingen. Stauffenburg.

SketchEngine: https://app.sketchengine.eu/\#dashboard?corpname=user\%2Fmirjanaborucinsky $\% 2 \mathrm{Fko}$ rpus_hrvatski_ozj 


\title{
LEXICAL INCOMPATIBILITIES OF VERB-NOUN COLLOCATIONS IN GERMAN, ENGLISH AND CROATIAN COMMON LANGUAGE OF SCIENCE AND THEIR REPRESENTATION IN E-DICTIONARIES OF GENERAL SCIENTIFIC TERMS
}

\author{
Mirjana Šnjarić \\ University of Zagreb, Faculty of Humanities and Social Sciences \\ mirjana.snjaric1@gmail.com
}

\begin{abstract}
The paper deals with transdisciplinary verb-noun collocations and their lexical incompatibilities in the German, English, and Croatian common language of science - e.g, Aspekt(e)/ /Problem(e) herausstellen '(to) highlight/emphasize/point out aspects', 'istaknuti/naglasiti aspekt(e)/ /problem(e)'. Contrastive and translation analysis is limited to selected examples of collocations in the German and English common language of science and a comparison with their contrastive correspondents in Croatian as well as the establishment of translation equivalents in the three languages.

One of the aims of the paper is to point out the need to create new types of multilingual and multipurpose electronic dictionaries with improved processing of general scientific verb-noun collocations. The second goal is to shed light on issues related to collocation in this area of language and to propose an improved and more detailed representation of inconsistent collocational patterns in the new trilingual e-dictionary of general scientific language based on confirmations of actual application in the wider syntagmatic environment in the modern corpus of scientific knowledge. Such a syntagmatic environment would depict and describe the type of scientific activity that takes place in collocational verb-noun patterns below the level of the isolated individual functional translation equivalent, and occupies an appropriate place in the structure of a scientific text in the three languages.

The ultimate goal of the first broader research of verb-noun collocations of three languages is to present and make a list of typical and characteristic general scientific collocations with translation equivalents or possible translation solutions, which should finally be described and presented in a new trilingual electronic dictionary of transdisciplinary general scientific terminology of the three languages.

The modern corpus of the Croatian scientific language was used as the source for Croatian verb-noun collocations. The German online dictionary Digitales Wörterbuch der deutschen Sprache (DWDS) served as a source of collocation information for the German language, while the online dictionaries Glosbe and Langenscheidt were used as a source for English collocations.
\end{abstract}

Keywords: general scientific language; transdisciplinary verb + noun collocations; Croatian; German; English; language of science; trilingual collocational e-dictionary 